\title{
Morphological, Biochemical, and Serological Characterization of Rothia dentocariosa
}

\author{
R. J. LESHER, M. A. GERENCSER, and V. F. GERENCSER \\ Department of Microbiology, West Virginia University School of Medicine, Morgantown, \\ West Virginia 26506
}

\begin{abstract}
Fifty strains of Rothia dentocariosa Georg and Brown were characterized morphologically, biochemically, and serologically. All strains had characteristics agreeing with previous morphological descriptions of this organism, although there was greater biochemical and serological strain variation than previously reported. Four biotypes were established on the basis of variability in reduction of nitrite, production of urease, hydrolysis of esculin, and formation of acid from lactose, mannitol, mannose, raffinose, rhamnose, salicin, and trehalose. Three serotypes and a group of fluorescent antibody-negative strains were identified on the basis of the fluorescent antibody technique. A relationship between the four biotypes and the three serotypes was established.
\end{abstract}

The monospecific genus Rothia, with type species Rothia dentocariosa, was proposed by Georg and Brown (2) to accommodate microorganisms previously designated as $A c t i$ nomyces dentocariosus, Nocardia dentocariosus, and Nocardia salivae. Brown, Georg, and Waters (1) subsequently studied 50 isolates having the morphological and biochemical characteristics of Rothia. Hammond (3) showed that all of his strains of $R$. dentocariosa contained a soluble polysaccharide antigen (RPS), and the detection of this antigen by the fluorescent-antibody (FA) technique is useful in identifying this organism.

Rothia is included in the family Actinomy. cetaceae because of its branching, filamentous morphology and its ability to septate into bacillary, diphtheroidal, or coccal cells, or a mixture of these; its colonial morphology, including spider microcolonies and mature colonies which may be heaped and rough or entirely smooth; and its cell wall composition. However, Rothia differs from the genera Actinomyces, Arachnia, Bifidobacterium, and Bacterionema in its aerobic tendencies, its production of catalase, its lack of growth stimulation by $\mathrm{CO}_{2}$, and its production of lactose as the major end product from glucose fermentation.

Among the organisms isolated from dental calculus in this laboratory were a number of filamentous, aerobic, gram-positive, catalasepositive strains resembling Rothia morphologically but possessing variant biochemical reactions and not reacting with antisera prepared with the neotype strain of $R$. dentocariosa, ATCC 17931. Similar aberrant strains have been submitted by others to the Center for Disease Control for identification (L. Georg, personal communication).

By comparing the morphological, biochemical, and serological characteristics of Rothia with Rothia-like organisms, we hope to clarify the uncertain status of the latter.

\section{MATERIALS AND METHODS}

Bacterial strains. The sources and designations of the fifty strains used in this study are given in Table 1.

All cultures were maintained by monthly transfer on tryptic soy agar (TSA) (Difco) slants. Prior to use, the cultures were transferred twice in tryptic soy broth (TSB) (Difco).

Colonial morphology. TSB cultures were streaked onto two TSA plates and incubated aerobically and anaerobically at $37 \mathrm{C}$. The anaerobic plate was incubated in a Torbal jar containing $\mathrm{N}_{2}: \mathrm{H}_{2}: \mathrm{CO}_{2}$ $(80: 20: 10)$. Microcolonies were observed after 18 and $24 \mathrm{~h}$ of incubation at a magnification of $\times 100$ to $\times 400$. Mature colonies were observed at $\times 25$ to $\times 40$ after 7 days of incubation.

Cellular morphology. Gram-stained smears and wet mounts for dark-field microscopy were prepared and examined from 2- and 7-day-old cultures in TSB and on TSA.

Biochemical Tests. Tests for catalase, indole, nitrate reduction, nitrite reduction, esculin hydrolysis, gelatin liquefaction, hydrogen sulfide production using BHI agar, urease production, and the production of acid from carbohydrates were done by the methods of Brown et al. (1).

Additional biochemical tests used were growth on 
Sabouraud dextrose agar (Difco), liquefaction of Loeffler coagulated serum (BBL) slants, digestion of casein, hydrolysis of hippurate, deoxyribonuclease production, production of ammonia from arginine, and the oxidation-fermentation (O-F) test (5).

DNase test agar (BBL) was inoculated and incubated for 7 days. After incubation, the plates were flooded with $1 \mathrm{~N} \mathrm{HCl}$ and observed for the formation of clear zones around the colonies.

TSB broth containing $1.0 \%$ sodium hippurate was inoculated and incubated for 7 days. The cultures were centrifuged, and $1.0 \mathrm{ml}$ of supernatant was added to $1.5 \mathrm{ml}$ of $50 \% \quad \mathrm{H}_{2} \mathrm{SO}_{4}$. After $4 \mathrm{~h}$ at room temperature, the tubes were observed for the formation of flat crystals of benzoic acid.

The production of ammonia from arginine was tested after 7 and 14 days. The basal medium contained the following: yeast extract, $0.1 \%$; Trypticase, $0.1 \% ; \mathrm{K}_{2} \mathrm{PO}_{4}, 0.03 \%$; and $\mathrm{NaCl}, 0.5 \%$. The test medium also contained $0.3 \%$ arginine. Duplicate tubes of basal and test media were inoculated and tested for ammonia production by mixing $1.0 \mathrm{ml}$ of each medium with $1.0 \mathrm{ml}$ of Nessler reagent and observing for the formation of a deep orange to brick-red color in the presence of ammonia.

The oxidation-fermentation test was performed as described by Hugh and Leifson (5). The medium used to test for fermentation of glucose contained $24 \mathrm{~g}$ of

TABLE 1. Sources of strains studied

\begin{tabular}{ll}
\hline \multicolumn{1}{c}{ WVU $^{a}$ number } & \\
\hline Rothia dentocariosa & \\
477 & Previous designation and source \\
478 & CDC 808 ${ }^{b}$, leg-stump drainage \\
479 & CDC W853, throod \\
1317 & WVU isolate, dental calculus \\
1489 & ATCC 17931 , type strain human dentine \\
1524 & ATCC 14189 \\
1525 & ATCC 14190 \\
1526 & ATCC 14191 \\
1560 & I. R. Rothenberg 25684, sputum \\
1562 & I. R. Rothenberg 28342, sputum \\
& \\
Rothia-like & \\
$804,841,842$ & WVU isolates, dental calculus \\
$858,874,918$ & \\
$936,945,972$ & \\
$992,997,999$ & \\
$1013,1027,1072$ & \\
$1073,1088,1192,1200$ & \\
1532 & \\
1533 & CDC W874a, throat \\
1534 & CDC X599a, throat \\
1535 & CDC W1581 \\
1536 & CDC W1591, eye \\
1537 & CDC X566aS \\
1538 & CDC X5486, sputum \\
1539 & CDC W1535, throat \\
1540 & CDC X667, sputum \\
1541 & CDC X666, throat \\
1549 & CDC X690 \\
1550 & CDC W1578, sputum \\
1551 & CDC W712, sputum \\
1552 & CDC W874B, throat \\
1553 & CDC X368, CSF \\
1554 & CDC X569g, Roth D108 \\
1555 & CDC X358, Davis BC1 \\
1556 & CDC X359, Davis NSE210 \\
1557 & CDC X483, blood \\
1558 & CDC W781, throat \\
1559 & CDC X303, NCTC 10207 \\
\hline
\end{tabular}

${ }^{a}$ WVU, West Virginia University, Morgantown, W. Va.

${ }^{b}$ CDC, Center for Disease Control, Atlanta, Ga.; all cultures provided by L. Georg.

c American Type Culture Collection, Rockville, Md. 
fluid thioglycolate medium without glucose or indicator (BBL) per liter in addition to the components suggested by Hugh and Liefson (5).

Serological tests. Strains (WVU 477, 936, 999, 1088 , and 1489) were used for antiserum production. Cells grown in TSB at $37 \mathrm{C}$ for $24 \mathrm{~h}$ were harvested by centrifugation, washed twice in sterile saline, resuspended in saline to a turbidity of a no. 4 MacFarland tube, and stored in 4-ml quantities at $-30 \mathrm{C}$.

For immunization, one vial of antigen was thawed prior to injection. The immunization schedule is given in Table 2.

The procedures used for determining the working titer of the conjugate and for staining the smears were essentially the same as those described by Slack, Landfried, and Gerencser (6).

Sorption of the antisera was done by incubating 1 $\mathrm{ml}$ of a $1: 2$ dilution of the conjugate with $0.1 \mathrm{ml}$ of washed, packed cells of the sorbing strain at $56 \mathrm{C}$ for 1 $h$ followed by overnight refrigeration. The conjugate was removed from the cells by centrifugation, and the sorption was repeated. A sorbed antiserum was considered satisfactory if it stained the homologous strain with an intensity of $4+$ at a final dilution of $1: 40$ and did not stain the sorbing strain at $1: 2$.

\section{RESULTS}

Cellular morphology. Cells in TSA and TSB were gram positive and pleomorphic; coccoid, cocco-bacillary, and filamentous forms were present. Cultures would occasionally be completely coccoid or diphtheroidal. Aging cultures tended to become gram negative.

Colonial morphology. Young (18- to 24-hold) colonies on TSA plates averaged $1 \mathrm{~mm}$ in diameter. When examined with a microscope, young colonies grown aerobically were granular with entire borders, whereas those grown anaerobically were granular with filamentous borders.

TABLE 2. Immunization schedule for production

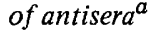

\begin{tabular}{cc}
\hline Injection & Time interval (days) \\
\hline 1 & 1 \\
2 & 3 \\
3 & 7 \\
4 & 10 \\
5 & 14 \\
6 & 17 \\
7 & 25 \\
8 & 28 \\
9 & 31 \\
$10^{b}$ & 35 \\
\hline
\end{tabular}

${ }^{a}$ Amount of antigen injected was $1 \mathrm{ml}$. This same schedule used for all antigens prepared.

${ }^{b}$ Animals were bled by cardiac puncture 1 week after last injection.
TABLE 3. Biochemical reactions of 50 Rothia strains

\begin{tabular}{|c|c|c|}
\hline Test & $\begin{array}{c}\text { No. } \\
\text { positive }\end{array}$ & $\begin{array}{c}\% \\
\text { Positive }\end{array}$ \\
\hline Catalase production & 50 & 100 \\
\hline Indole production $\ldots \ldots \ldots$. & 0 & 0 \\
\hline Nitrate reduction .... & 48 & 96 \\
\hline Nitrite reduction $(0.001 \%)$ & 44 & 88 \\
\hline Nitrite reduction $(0.01 \%)$. & 33 & 66 \\
\hline Esculin hydrolysis . . . . . . . & 47 & 94 \\
\hline Urease production ........ & 10 & 20 \\
\hline Deoxyribonuclease production & 45 & 90 \\
\hline Gelatin liquefaction $\ldots \ldots \ldots$ & 0 & 0 \\
\hline Casein hydrolysis $\ldots \ldots \ldots \ldots$ & 0 & 0 \\
\hline Serum liquefaction .... & 0 & 0 \\
\hline \multicolumn{3}{|l|}{ Acid from: $:^{a}$} \\
\hline Glucose . & 50 & 100 \\
\hline Glycerol ... & 50 & 100 \\
\hline Lactose ......... & 11 & 22 \\
\hline Maltose ... & 50 & 100 \\
\hline Mannose . . . . . . . . . & 46 & 92 \\
\hline 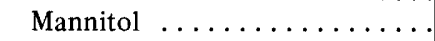 & 10 & 20 \\
\hline Raffinose ......... & 10 & 20 \\
\hline Rhamnose $\ldots . \ldots \ldots$ & 14 & 28 \\
\hline Ribose ........ & 35 & 70 \\
\hline Salicin ....... & 42 & 84 \\
\hline Sucrose $\ldots \ldots \ldots$ & 50 & 100 \\
\hline Trehalose $\ldots \ldots \ldots \ldots$ & 44 & 88 \\
\hline
\end{tabular}

${ }^{a}$ None of the strains fermented adonitol, arabinose, cellobiose, glycogen, inositol, sorbitol, starch, or xylose.

Mature colonies ( 7 to 14 days) were creamy white in color and varied from 1 to $4 \mathrm{~mm}$ in diameter and from smooth to rough. Smooth colonies were convex with a finely granular surface and entire edges; rough colonies were convex with convoluted, highly cerebriform surfaces, and undulate or scalloped edges. The texture of both colony types varied from mucoid to friable. Both forms could be seen in the same culture.

Biochemical tests. The results of the biochemical tests are shown in Table 3. All strains were catalase positive, indole negative, and hippurate-hydrolysis negative; none of the strains produced ammonia from arginine or liquefied gelatin, digested casein, or liquefied Loeffler serum slants.

Nitrite reduction was variable and was dependent on the concentration of the $\mathrm{KNO}_{2}$ used in the test medium. In the original test for nitrite reduction, which required $0.01 \% \mathrm{KNO}_{2}$, only $66 \%$ of the strains were positive. Further testings using the same medium, with the nitrite concentration reduced to $0.001 \% \quad \mathrm{KNO}_{2}$, resulted in better growth and increased positive reactions $(88 \%)$. 
Serology. The results of the cross-staining and the reciprocal-sorption studies with the five strains used for antiserum production are shown in Table 4 . These results suggested that strains 936 and 999 were serologically distinct from the other strains and were closely related, if not identical. Relationships between the other three strains were more complex and have not been completely worked out; however, the sorption studies suggest that the type strain, 1489 , is different from strains 477 and 1088 . The latter strains are not identical but are more closely related to each other than to 1489 . With this as a basis, all 50 strains were tested with each of the antisera, and positive strains were retested with the appropriate sorbed sera. Six strains were FA negative with all five sera. Nine strains reacted to titer with either 936 or 999 sera, or with both. Eight of these strains showed no reactions or minimal reactions with the other sera. One strain reacted strongly with 1489 as well as with 936 and 999 sera. The remaining 35 strains reacted with one or more of the 1489,477 , and 1088 sera. When tested with sorbed sera, some strains stained only with 1489 or with 477 or 1088 sera, again suggesting that these strains represent two serotypes. However, some cultures which had been positive with unsorbed sera did not react with any of the sorbed sera, making their placement in one of the two serotypes uncertain. At present these 35 strains can be divided into two serotypes: type 1 with 10 strains and type 2 with 15 strains. A group of 10 strains showed relationship to both serotypes.

Classification. Using both biochemical and serological results, the 50 strains could be divided into four biotypes and three serotypes (Table 5).

The establishment of the four biotypes involved variability in the reduction of $\mathrm{NO}_{2}$ when the $\mathrm{KNO}_{2}$ concentration in the basal medium was $0.01 \%$, the production of urease, the hydrolysis of esculin, and the production of acid from mannose, salicin, trehalose, lactose, mannitol, raffinose, and rhamnose. Biotype 1 strains were characterized by biochemical reactions which agreed with those previously reported for the species in that they reduced $\mathrm{NO}_{2}(100 \%)$, were urease negative $(100 \%)$ and esculin positive $(100 \%)$, produced acid from mannose $(100 \%)$, salicin $(100 \%)$, trehalose $(100 \%)$, and rhamnose $(4 \%)$, and did not produce acid from lactose, mannitol, or raffinose. Biotype 2 strains did not reduce $\mathrm{NO}_{2}$, were urease negative and esculin positive $(100 \%)$, produced acid from mannose $(57 \%)$, salicin $(28 \%)$, trehalose $(57 \%)$, lactose $(28 \%)$, and rhamnose $(14 \%)$, and did not produce acid
TABLE 4. Serological reactions of strains of Rothia ${ }^{a}$

\begin{tabular}{|c|c|c|c|c|c|c|}
\hline \multirow[b]{2}{*}{ Antiserum } & \multirow{2}{*}{$\begin{array}{c}\text { Sorbed } \\
\text { with }\end{array}$} & \multicolumn{5}{|c|}{ Strain } \\
\hline & & 477 & 1088 & 1489 & 936 & 999 \\
\hline \multirow[t]{3}{*}{1489} & & - & _- & + & - & - \\
\hline & 477 & - & - & + & - & - \\
\hline & 1088 & - & - & + & - & - \\
\hline \multirow[t]{3}{*}{477} & & + & + & + & - & - \\
\hline & 1088 & + & - & - & - & - \\
\hline & 1489 & + & - & - & - & - \\
\hline \multirow[t]{3}{*}{1088} & & + & + & - & - & - \\
\hline & 477 & - & - & - & - & - \\
\hline & 1489 & + & + & - & - & - \\
\hline 936 & & - & - & - & + & + \\
\hline \multirow[t]{2}{*}{999} & & - & - & - & + & + \\
\hline & 936 & - & - & - & - & - \\
\hline
\end{tabular}

${ }^{a}$ Symbols: $+=$ or greater fluorescence at working titer (unsorbed sera) or at $1: 2$ (sorbed sera); $-=$ less than $2+$ fluorescence undilated (unsorbed) or 1:2 (sorbed).

from mannitol or raffinose. Biotype 3 strains reduced $\mathrm{NO}_{2}(63 \%)$, were urease positive $(100 \%)$ and esculin positive $(86 \%)$, and produced acid from mannose $(86 \%)$, salicin $(71 \%)$, trehalose $(71 \%)$, lactose $(50 \%)$, mannitol $(14 \%)$, raffinose $(14 \%)$, and rhamnose $(29 \%)$. Biotype 4 strains reduced $\mathrm{NO}_{2}(80 \%)$, were urease positive $(27 \%)$ and esculin positive $(82 \%)$, and produced acid from mannose $(100 \%)$, salicin $(91 \%)$, trehalose $(91 \%)$, lactose $(50 \%)$, mannitol $(82 \%)$, raffinose $(82 \%)$, and thamnose $(91 \%)$. In all biotypes, any strain which was anomolous in a sugar fermentation usually differed with respect to several sugars so that a strain which failed to ferment mannose usually also failed to ferment ribose, salicin, and trehalose; strains which fermented a sugar such as lactose often also fermented rhamnose.

Serologically, 25 of the 39 strains included in biotypes 1 to 3 belonged to serotypes 1 or 2 , and 10 strains showed some relationship to both serotypes. Since strains in biotypes 2 and 3 were serologically related to biotype 1 , all 39 strains were identified as Rothia dentocariosa.

Biotype 4 strains showed some intertype variability in the tests used in separating biotypes 1 to 3 , especially the urease test. However, these strains were consistently more active in fermentation reactions than were strains of biotypes 1 to 3 . Ten of the 11 strains fermented either mannitol or raffinose, and seven fermented both. These seven strains also 
INT. J. SYST. BACTERIOL.

TABLE 5. Characteristics of biotypes of Rothia

\begin{tabular}{|c|c|c|c|c|c|c|c|c|}
\hline \multirow[b]{3}{*}{ Test } & \multicolumn{8}{|c|}{ Biotype } \\
\hline & \multicolumn{2}{|c|}{$\begin{array}{c}1 \\
\text { (25 strains) }\end{array}$} & \multicolumn{2}{|c|}{$\begin{array}{c}2 \\
\text { (7 strains) }\end{array}$} & \multicolumn{2}{|c|}{$\begin{array}{c}3 \\
\text { (7 strains) }\end{array}$} & \multicolumn{2}{|c|}{$\begin{array}{c}4 \\
\text { (11 strains) }\end{array}$} \\
\hline & $\begin{array}{c}\text { No. } \\
\text { positive }\end{array}$ & $\begin{array}{c}\% \\
\text { positive }\end{array}$ & $\begin{array}{c}\text { No. } \\
\text { positive }\end{array}$ & $\begin{array}{c}\% \\
\text { positive }\end{array}$ & $\begin{array}{l}\text { No. } \\
\text { positive }\end{array}$ & $\begin{array}{c}\% \\
\text { positive }\end{array}$ & $\begin{array}{c}\text { No. } \\
\text { positive }\end{array}$ & $\begin{array}{c}\% \\
\text { positive }\end{array}$ \\
\hline Catalase & 0 & 0 & 0 & 0 & 0 & 0 & 0 & 0 \\
\hline Indole. & 0 & 0 & 0 & 0 & 0 & 0 & 0 & 0 \\
\hline Nitrate & 25 & 100 & 6 & 85 & 6 & 6 & 11 & 100 \\
\hline Nitrite $(0.001 \%)$ & 25 & 100 & & & 5 & 63 & 8 & 80 \\
\hline Nitrite $(0.01 \%)$. & 21 & 84 & 4 & 57 & 4 & 50 & 4 & 40 \\
\hline Esculin $\ldots \ldots$ & 25 & 100 & 7 & 100 & 6 & 86 & 9 & 82 \\
\hline Urease $\ldots .$. & 0 & 0 & 0 & 0 & 7 & 100 & 3 & 27 \\
\hline Deoxyribonuclease $\ldots .$. & 24 & 96 & 4 & 57 & 6 & 86 & 11 & 100 \\
\hline Gelatin liquefaction ...... & 0 & 0 & 0 & 0 & 0 & 0 & 0 & 0 \\
\hline Casein hydrolysis $\ldots \ldots \ldots$ & 0 & 0 & 0 & 0 & 0 & 0 & 0 & 0 \\
\hline Serum liquefaction ....... & 0 & 0 & 0 & 0 & 0 & 0 & 0 & 0 \\
\hline \multicolumn{9}{|l|}{ Acid from: ${ }^{a}$} \\
\hline Glucose & 25 & 100 & 7 & 100 & 7 & 100 & 11 & 100 \\
\hline Glycerol ... & 25 & 100 & 7 & 100 & 7 & 100 & 11 & 100 \\
\hline Lactose .... & 0 & 0 & 2 & 28 & 4 & 50 & 5 & 50 \\
\hline Maltose .... & 25 & 100 & 7 & 100 & 7 & 100 & 11 & 100 \\
\hline Mannose .... & 25 & 100 & 4 & 57 & 6 & 86 & 11 & 100 \\
\hline Mannitol ... & 0 & 0 & 0 & 0 & 1 & 14 & 9 & 82 \\
\hline Raffinose .... & 0 & 0 & 0 & 0 & 1 & 14 & 9 & 82 \\
\hline Rhamnose & 1 & 4 & 1 & 14 & 2 & 29 & 10 & 91 \\
\hline Ribose ...... & 22 & 88 & 1 & 14 & 2 & 29 & 10 & 91 \\
\hline Salicin ... & 25 & 100 & 2 & 28 & 5 & 71 & 10 & 91 \\
\hline Sucrose $\ldots \ldots \ldots \ldots \ldots$ & 25 & 100 & 7 & 100 & 7 & 100 & 11 & 100 \\
\hline Trehalose.............. & 25 & 100 & 4 & 57 & 5 & 71 & 10 & 91 \\
\hline Serotype 11489 . & \multicolumn{2}{|c|}{6} & \multicolumn{2}{|c|}{2} & \multicolumn{2}{|c|}{2} & \multicolumn{2}{|c|}{0} \\
\hline Serotype $2477 .$. & \multicolumn{2}{|c|}{9} & \multicolumn{2}{|c|}{3} & \multicolumn{2}{|c|}{3} & \multicolumn{2}{|c|}{0} \\
\hline Serotype $3936 \ldots$ & \multicolumn{2}{|c|}{0} & \multicolumn{2}{|c|}{0} & \multicolumn{2}{|c|}{0} & \multicolumn{2}{|c|}{9} \\
\hline Serotype FA negative .. & \multirow{2}{*}{\multicolumn{2}{|c|}{$\begin{array}{l}3 \\
7\end{array}$}} & \multirow{2}{*}{\multicolumn{2}{|c|}{$\begin{array}{l}1 \\
1\end{array}$}} & \multirow{2}{*}{\multicolumn{2}{|c|}{$\begin{array}{l}0 \\
2\end{array}$}} & \multirow{2}{*}{\multicolumn{2}{|c|}{$\begin{array}{l}2 \\
0\end{array}$}} \\
\hline $1 \& 2$ related $\ldots \ldots$ & & & & & & & & \\
\hline
\end{tabular}

${ }^{a}$ All strains were negative in adonitol, arabinose, cellobiose, glycogen, inositol, sorbitol, starch, and xylose.

fermented lactose. Nine of the strains were apparently identical serologically and were unrelated to the serotypes found in biotypes 1 to 3 .

\section{DISCUSSION}

The 50 strains of gram-positive bacteria studied conform to the morphological description of the genus Rothia $(1,2)$. All strains were pleomorphic with coccoid, cocco-bacillary, and filamentous forms. There was a distinct tendency for some cultures to be completely coccoid or diphtheroidal. Among the Actinomycetaceae, only Arachnia propionica shares with Rothia this characteristic of converting to completely coccoid morphology.
The colonies produced by the strains studied presented a variety of types, but both microcolony and mature colony types were within the range of types described for the species by Brown et al. (1).

The results of the physiological tests were more strain variable than those reported by Brown et al. (1).

All strains were aerobic and catalase positive and fermented carbohydrates (O-F test) with the production of acid with no gas. On the basis of these characteristics and their morphology, all 50 strains were classified as belonging to Rothia.

In view of the remarkably uniform reactions of strains of $R$. dentocariosa, the single species in this genus, the major consideration was 
whether biochemically variant strains should be placed in this species and, if so, how much variation should be accepted.

All strains of biotypes 1 to 3 (Table 5) were identified as Rothia dentocariosa. Biotype 1 presented the uniform biochemical picture expected of $R$. dentocariosa and generally agreed with previous descriptions of the species. Biotypes 2 and 3 were related to biotype 1 serologically, so it was decided to include them in $R$. dentocariosa.

An increased strain variation can be expected in biochemical tests, and inclusion of such variable strains in the species should make it easier for laboratories to identify fresh isolates. It should be remembered that these strains tend to have several aberrant characters, especially the failure to ferment three or all of the sugars mannose, ribose, salicin, and trehalose.

The serological relationships within biotypes 1 to 3 need to be clarified. The four FA-negative strains and the 10 strains showing some relationship to both serotypes 1 and 2 suggest that further serotypes may exist. Identification of the distinctive polysaccharide antigen (RPS) described by Hammond (3) in these strains might help to elucidate the antigenic relationships.

The 11 strains included in biotype 4 were serologically distinct. Only one strain in biotypes 1 to 3 showed any serological cross-reaction with biotype 4 antiserum. Another serotype 1 strain resembled biotype 4 strains in fermenting mannitol and raffinose. For these reasons, we feel that it is definitely premature to exclude these 11 strains from $R$. dentocariosa, but it also seems undesirable to classify them as such at present. Therefore, we would prefer to retain them as Rothia sp. biotype 4 .

Before a final decision is made as to the suggestion of a new species with the genus
Rothia for biotype 4 strains, further studies, including deoxyribonucleic acid base ratios and homologies, are required.

\section{ACKNOWLEDGMENTS}

This investigation was supported in part by Public Health Service NIDR Training Grant 5T01-DE0024904.

We would also like to thank J. M. Slack for his help in the preparation of this manuscript.

\section{REPRINT REQUESTS}

Address reprint requests to: Dr. R. J. Lesher, Department of Microbiology, West Virginia University School of Medicine, Morgantown, W. Va. 26506.

\section{LITERATURE CITED}

1. Brown, J. M., L. K. Georg, and L. C. Waters. 1969. Laboratory identification of Rothia dentocariosa and its occurrence in human clinical material. Appl. Microbiol. 17:150-156.

2. Georg, L. K., and J. Brown. 1967. Rothia, gen nov. an aerobic genus of the family Actinomycetaceae. Int. J. Syst. Bacteriol. 17:79-88.

3. Hammond, B. F. 1970. Isolation and serological characterization of a cell wall antigen of Rothia dentocariosa. J. Bacteriol. 103:634-640.

4. Hebert, G. A., B. Pittman, R. M. McKinney, and W. B. Cherry. 1972. The preparation and physiochemical characterization of fluorescent antibody reagents. Center for Disease Control, Laboratory Division, Atlanta, Ga.

5. Hugh, R., and E. Leifson. 1953. The taxonomic significance of fermentative versus oxidative metabolism of carbohydrates by various gramnegative bacteria. J. Bacteriol. 66:24-26.

6. Slack, J. M., S. Landfried, and M. A. Gerencser. 1971. Identification of Actinomyces and related bacteria in dental calculus by the fluorescent antibody technique. J. Dent. Res. 50:78-82. 